\title{
Population-specific vital rate contributions influence management of an endangered ungulate
}

\author{
Heather E. Johnson, ${ }^{1,4}$ L. Scott Mills, ${ }^{1}$ Thomas R. Stephenson, ${ }^{2}$ and John D. Wehausen ${ }^{3}$ \\ ${ }^{1}$ University of Montana, Wildlife Biology Program, College of Forestry and Conservation, Missoula, Montana 59812 USA \\ ${ }^{2}$ Sierra Nevada Bighorn Sheep Recovery Program, California Department of Fish and Game, \\ 407 West Line Street, Bishop, California 93514 USA \\ ${ }^{3}$ White Mountain Research Station, University of California, 3000 East Line Street, Bishop, California 93514 USA
}

\begin{abstract}
To develop effective management strategies for the recovery of threatened and endangered species, it is critical to identify those vital rates (survival and reproductive parameters) responsible for poor population performance and those whose increase will most efficiently change a population's trajectory. In actual application, however, approaches identifying key vital rates are often limited by inadequate demographic data, by unrealistic assumptions of asymptotic population dynamics, and of equal, infinitesimal changes in mean vital rates. We evaluated the consequences of these limitations in an analysis of vital rates most important in the dynamics of federally endangered Sierra Nevada bighorn sheep (Ovis canadensis sierrae). Based on data collected from 1980 to 2007, we estimated vital rates in three isolated populations, accounting for sampling error, variance, and covariance. We used analytical sensitivity analysis, life-stage simulation analysis, and a novel non-asymptotic simulation approach to (1) identify vital rates that should be targeted for subspecies recovery; (2) assess vital rate patterns of endangered bighorn sheep relative to other ungulate populations; (3) evaluate the performance of asymptotic vs. non-asymptotic models for meeting short-term management objectives; and (4) simulate management scenarios for boosting bighorn sheep population growth rates. We found wide spatial and temporal variation in bighorn sheep vital rates, causing rates to vary in their importance to different populations. As a result, Sierra Nevada bighorn sheep exhibited population-specific dynamics that did not follow theoretical expectations or those observed in other ungulates. Our study suggests that vital rate inferences from large, increasing, or healthy populations may not be applicable to those that are small, declining, or endangered. We also found that, while asymptotic approaches were generally applicable to bighorn sheep conservation planning, our non-asymptotic population models yielded unexpected results of importance to managers. Finally, extreme differences in the dynamics of individual bighorn sheep populations imply that effective management strategies for endangered species recovery may often need to be population-specific.
\end{abstract}

Key words: endangered species; management; Ovis canadensis sierrae; population models; recovery; Sierra Nevada bighorn sheep; ungulate; vital rates.

\section{INTRODUCTION}

If deterministic or stochastic factors trigger successive decreases in key vital rates, such as stage-specific survival and reproductive parameters, a population will decline, potentially to extinction. To develop effective management strategies for the recovery of threatened and endangered species, it is critical to identify those vital rates responsible for poor population performance and those whose increase will most efficiently change a population's trajectory (Morris and Doak 2002, Mills 2007). While the disproportionate impact of different vital rates on population growth is well recognized in basic and applied ecology (Crouse et al. 1987, Heppell et

Manuscript received 19 June 2009; revised 8 October 2009; accepted 19 October 2009; final version received 13 November 2009. Corresponding Editor: J. J. Millspaugh.

${ }^{4}$ E-mail: hjohnson@dfg.ca.gov al. 1996, Caswell 2001, Gaillard et al. 2001), it is still often overlooked in endangered species recovery programs. In many cases, detailed demographic data are unavailable, but even when they exist the application of vital rate analyses in conservation planning is often not prioritized. As a result, well-intended conservation programs have misdirected their efforts toward increasing survival or reproductive parameters relatively inconsequential to population recovery efforts (Heppell et al. 1996).

Given the lack of demographic data on many small and endangered populations, it has been suggested that important vital rates identified in other populations of the same species, or those from similar species, be used to guide conservation efforts. The logic behind this is that demographic trends among species with analogous life-history traits should be comparable and thus, information on the importance of vital rates from well- 
studied populations should be applicable to those for which there is little information (Silvertown et al. 1996, Heppell 1998, Sæther and Bakke 2000). While the application of life-history expectations to the management of small or declining populations seems intuitive, its relevance has not been well evaluated. In fact, some long-term studies examining the dynamics of declining populations have reported that the most influential vital rates do not follow life-history expectations (OwenSmith and Mason 2005, Schmidt et al. 2005). As a result, it remains unclear whether demographic trends in endangered or declining populations do indeed mirror those from large or healthy populations, and if inferences among populations are appropriate.

When demographic data on endangered species are available, the most popular tools for assessing the relative significance of different vital rates are analytical sensitivity and elasticity analyses (de Kroon et al. 2000, Heppell et al. 2000, Morris and Doak 2002). These matrix-based approaches identify vital rates whose equal and infinitesimal changes have the greatest effect on population growth. In usual application these metrics rely on asymptotic properties of population matrices, assuming populations have constant mean vital rates, have converged to stable stage distribution (SSD), and are large enough to be unaffected by demographic stochasticity (although stochastic sensitivities and elasticities can be calculated; see Tuljapurkar et al. 2003, Morris and Doak 2005).

Assumptions inherent in traditional analytical analyses (asymptotic properties and equal, infinitesimal changes in vital rates) are limiting for most conservation applications. First, many small populations deviate from SSD and are subject to high demographic stochasticity (Bierzychudek 1999, Clutton-Brock and Coulson 2002, Fefferman and Reed 2006), causing asymptotic approaches to potentially misguide critical management efforts, particularly over short time periods (Fox and Gurevitch 2000, Merrill et al. 2003, Yearsley 2004, Koons et al. 2005, 2006). The second assumption of equal, infinitesimal changes in mean vital rates ignores the amount of variation that realistically occurs in those rates (Mills et al. 1999, 2001, Wisdom et al. 2000, Norris and McCulloch 2003). For example, in ungulate populations Gaillard et al. (1998) concluded that adult female survival consistently had the highest elasticity (and thereby had the greatest infinitesimal effect on population growth), but had inherently low variability, allowing little room for management to have an appreciable effect. Meanwhile, juvenile survival had low elasticity, but wide variation that was primarily responsible for changes in population size, and thus, the key vital rate to target for management purposes (see also Citta and Mills 1999, Gaillard et al. 2000, Wisdom et al. 2000, Raithel et al. 2007).

Recognition that the contribution of a vital rate to population growth largely depends on its actual range of variation has led to alternative methods of sensitivity analyses, including life-stage simulation analysis (LSA; Wisdom and Mills 1997, Wisdom et al. 2000). This approach readily incorporates variation (and covariation) among vital rates and allows investigators to simulate the effects of different management scenarios on population trajectories. Constrained by a lack of data on initial stage distribution and population size, most applications of LSA have relied on asymptotic properties of matrix models (Biek et al. 2002, Norris and McCulloch 2003, Hoekman et al. 2006, Raithel et al. 2007); however, this method could easily be extended to non-asymptotic projections with a specified initial stage vector and projection interval (Mills and Lindberg 2002).

In identifying vital rates driving the dynamics of small or endangered populations, the most useful sensitivity analyses should be those incorporating non-asymptotic dynamics and actual vital rate variation (present either in nature or under management). This would require data on vital rate means, variances and covariances, estimates of initial population size and stage distribution, and a projection interval of significance to managers. A unique data set allowed us to perform such an analysis on federally endangered Sierra Nevada bighorn sheep (Ovis canadensis sierrae [SNBS]; see Plate 1) and evaluate the influence of asymptotic assumptions on inferences about different vital rates. SNBS have the most restricted range and the fewest number of individuals of any subspecies of bighorn sheep in North America (U.S. Fish and Wildlife Service 2007). While currently there are populations of SNBS in five geographic areas, we focus only on three in this paper: Mono Basin, Wheeler Ridge (Wheeler), and Mount Langley (Langley). These herds are of particular interest because their mean vital rates, variances, and covariances can be estimated directly from annual survey data, and their population sizes and stage distributions are known. Using detailed demographic data on SNBS, we applied analytical sensitivity analysis, traditional (asymptotic) LSA, and a novel non-asymptotic extension of LSA to (1) identify vital rates that should be targeted for subspecies recovery, (2) assess vital rate patterns of endangered SNBS relative to other ungulate populations, (3) compare the performance of asymptotic vs. non-asymptotic models for meeting short-term SNBS management objectives, and (4) simulate management scenarios for boosting SNBS population performance.

\section{Study Area}

The Sierra Nevada mountain range forms the eastern backbone of California and is $\sim 650 \mathrm{~km}$ long and ranges from 75 to $125 \mathrm{~km}$ wide (Hill 1975). This range is an uplifted fault block with a steep eastern slope that has been sculpted by Pleistocene glaciers that created Ushaped canyons, steep cirque headwalls, and prominent peaks (Hill 1975). Historical and current distributions of SNBS include only the southern half of the Sierra Nevada, where these geologic processes have created the 


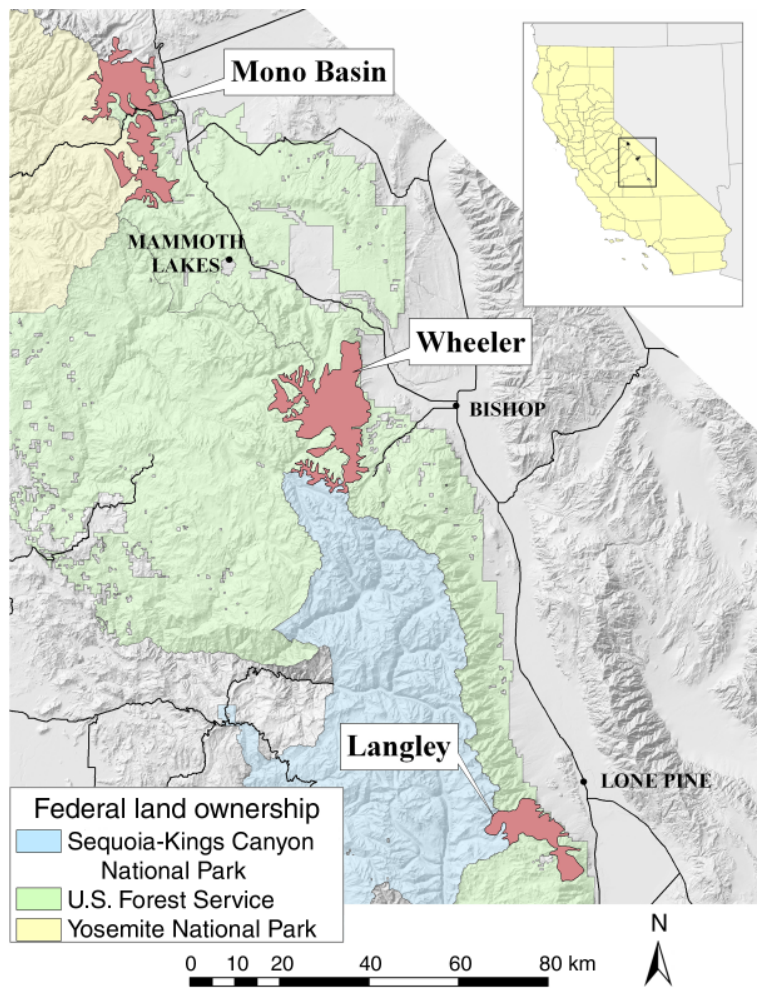

FIG. 1. Location of Mono Basin, Wheeler, and Langley Sierra Nevada bighorn sheep (Ovis canadensis sierrae) populations, California, USA.

highest mountains and the most alpine habitat. SNBS spend summers in the alpine along the crest of the Sierra Nevada and winters either in the alpine or at lower elevations typically east of the crest, inhabiting elevations ranging from 1525 to $>4000 \mathrm{~m}$ (U.S. Fish and Wildlife Service 2007). Climate in the Sierra Nevada is characterized by relatively dry conditions in summer (May-September), with most of the annual precipitation received as snow in winter (November-April), varying considerably by year. There is a strong rain shadow effect in precipitation east of the Sierra crest resulting in open, xeric vegetation communities. Low elevations $(1500-2500 \mathrm{~m})$ are characterized by Great Basin sagebrush-bitterbrush scrub; mid-elevations (2500-3300 m) by pinyon-juniper woodland, subalpine meadows, and forests; and high elevations $(>3300 \mathrm{~m})$ by sparse alpine vegetation including occasional meadows. Virtually all SNBS habitat is public land, managed primarily by Yosemite and Sequoia-Kings Canyon National Parks, and Inyo and Sierra National Forests.

\section{Methods}

\section{Vital rate parameter estimation}

We evaluated the three Sierra Nevada bighorn sheep (SNBS) populations for which extensive demographic data have been collected: Mono Basin, Wheeler Ridge (Wheeler), and Mount Langley (Langley). These herds were reintroduced in the late 1970s and 1980s (Bleich et al. 1990), with Mono Basin the northernmost population, Langley the southernmost, and Wheeler in the central part of the range (Fig. 1). Because SNBS is a highly valued endemic subspecies of California, annual surveys have been routinely conducted by California Department of Fish and Game (CDFG), the National Park Service, and independent biologists. All populations are known to be geographically isolated so that their dynamics are independent, and data from these herds encompass a wide range of spatial and temporal demographic variability (Fig. 2; see Appendix A for detailed population histories). After being reintroduced, the Wheeler and Langley populations remained relatively stationary until 1995, when they decreased slightly, and since then have dramatically increased. Consecutive annual surveys began in 1995 for Wheeler, and 1996 for Langley, so analyses of these populations are relevant to the period when these herds increased in size. Meanwhile, the Mono Basin population quickly grew following its reintroduction in 1986, and has subsequently declined (Fig. 2). Because annual surveys have been conducted since 1986, data from Mono Basin are analyzed across all years, and separately for the increasing and decreasing periods. Causes of such disparate population trends are not fully understood but suspected to be driven by differences in predation, habitat quality, and use of low-elevation winter ranges (U.S. Fish and Wildlife Service 2007).

During annual population surveys each herd unit was systematically hiked and scanned by experienced observers for bighorn sheep by sex and stage class. Field efforts focused specifically on counts of females and lambs, as they represent the reproductive segment of the population. The annual lambing period for SNBS occurs primarily from mid-April through mid-June, and females give birth to one offspring per year (Wehausen 1996). Surveys of the Wheeler population were conducted in late March or early April just before new lambs were born (pre-birth pulse), while surveys in

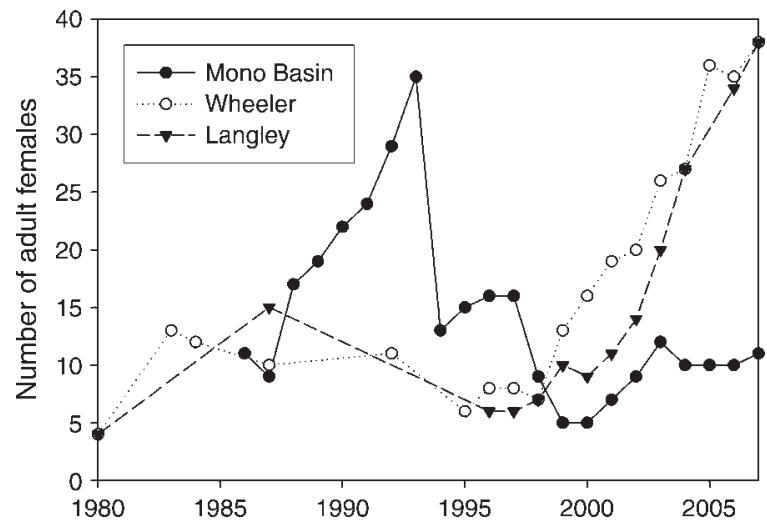

FIG. 2. Number of adult females in the Mono Basin, Wheeler, and Langley populations of Sierra Nevada bighorn sheep, 1980-2007. 


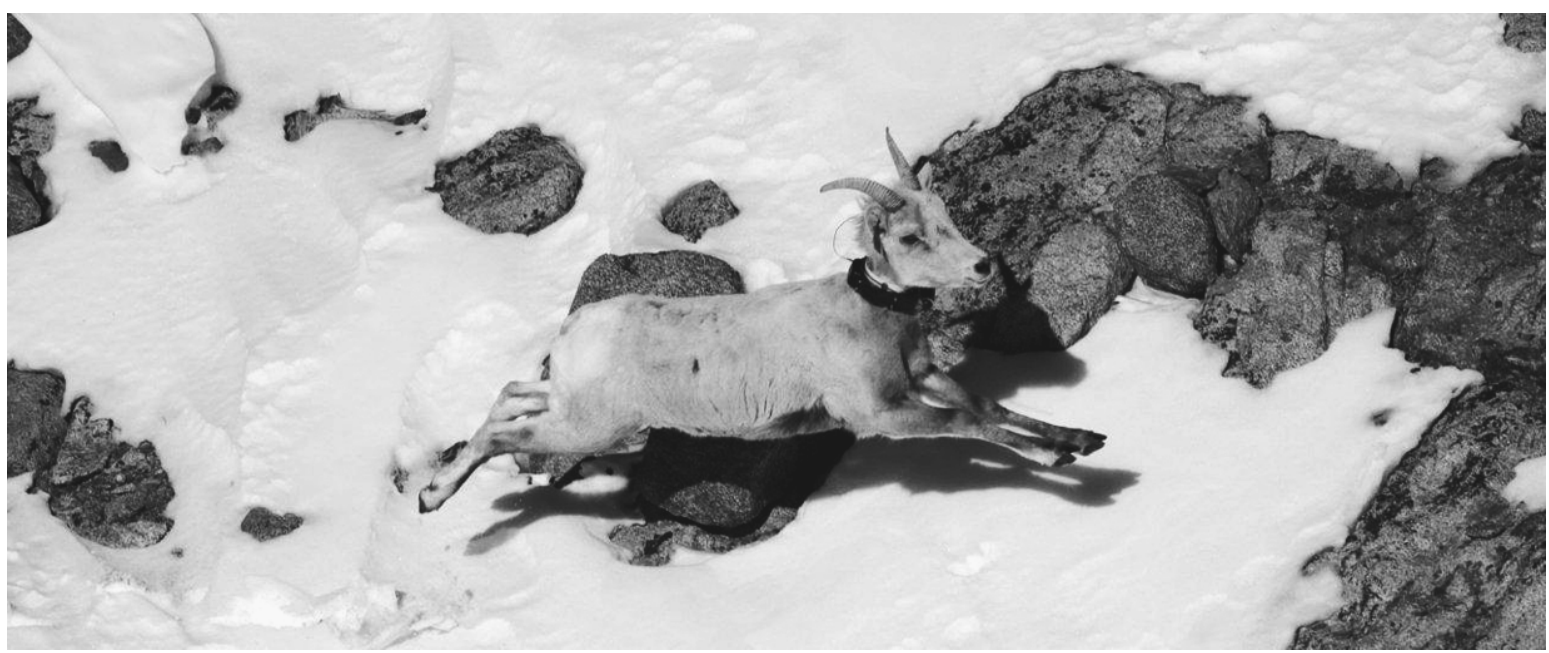

Plate 1. Adult female Sierra Nevada bighorn sheep. Photo credit: Tim Glenner.

Mono Basin and Langley were conducted in summer, just after new lambs were born (post-birth pulse).

Three stage classes were observed during both survey types; however, the timing of surveys resulted in distinct differences in the data collected that translate to different parameterizations of population projection matrices. During surveys at Wheeler (pre-birth pulse) observers counted the number of adult females $(\geq 2.7 \mathrm{yr}$; $\left.N_{\mathrm{A}}\right)$, two-year-old females $\left(\sim 1.7-1.9 \mathrm{yr} ; N_{\mathrm{T}}\right)$, and yearlings $\left(\sim 0.7-0.9 \mathrm{yr} ; N_{\mathrm{YS}}\right)$. Surveys at Mono Basin and Langley (post-birth pulse) counted the number of adult females $\left(\geq 2.1 \mathrm{yr} ; N_{\mathrm{A}}\right)$, yearling females $(\sim 1.1-1.3$ yr; $\left.N_{\mathrm{YL}}\right)$, and newborn lambs $\left(\sim 0.1-0.3 \mathrm{yr} ; N_{\mathrm{L}}\right)$. While yearlings are present in both survey types, we refer to individuals in this stage class as "short" yearlings $\left(N_{\mathrm{YS}}\right)$ in pre-birth pulse surveys, and "long" yearlings $\left(N_{\mathrm{YL}}\right)$ in the post-birth pulse surveys to acknowledge age differences of these animals observed in the field. All stage classes were uniquely identifiable by distinct horn and body size differences. Although "two-year-olds" (designated in pre-birth pulse surveys) are not typically classified in bighorn sheep studies, because these animals were not quite two-years-old (being $\sim 1.7-1.9 \mathrm{yr}$ ), this stage class could still be identified as their horns had not yet experienced a second season of growth. Annual surveys obtained minimum count data for each stage class, but due to intensive monitoring, repeated field efforts, and very small, observable populations (for example, numbers of adult females ranged from $\sim 5$ to 35 individuals in any population in any year), annual counts were highly successful at being near-complete censuses.

We used counts conducted during consecutive years to estimate annual population vital rates. Given the available data, different vital rates were calculated for pre- and post-birth pulse surveys. For the Wheeler population (sampled pre-birth pulse) we estimated adult female survival $\left(S_{\mathrm{A}}\right)$, two-year-old female survival $\left(S_{\mathrm{T}}\right)$, and recruitment $\left(R_{\mathrm{A}}\right)$. We calculated adult female survival in year $t$ as $N_{\mathrm{A}}(t) /\left(N_{\mathrm{A}}(t-1)+N_{\mathrm{T}}(t-1)\right)$. We calculated two-year-old survival as $N_{\mathrm{T}}(t) / N_{\mathrm{YS}}(t-1)$ and assumed equal survival among males and females because short yearlings at Wheeler were not consistently identified by sex in the field. Recruitment for year $t$ was calculated as $N_{\mathrm{YS}}(t) / N_{\mathrm{A}}(t-1)$. We assumed that twoyear-olds did not produce offspring, as ultrasonography on eight yearlings (captured from 2003 to 2009) found only one to be pregnant (CDFG, unpublished data). Because yearlings were not consistently distinguished by sex, yet small numbers of yearlings per year were subject to high demographic stochasticity, we did not assume a 50:50 sex ratio. Instead, we attempted to correct for known numbers of yearling females per adult female by using the number of two-year-old males and females in year $t+1$ to back-calculate minimum numbers of yearlings by sex in year $t$. Where yearling survival was $<1$ (i.e., not all yearlings survived to be two-year-olds and thus, there were yearlings counted in year $t$ not accounted for as two-year-olds in $t+1$ ), we assigned a 50:50 sex ratio to the remaining animals of unknown gender.

For Mono Basin and Langley, populations surveyed just after the lambing period, we estimated adult female survival $\left(S_{\mathrm{A}}\right)$, yearling female survival $\left(S_{\mathrm{Y}}\right)$, and fecundity $\left(F_{\mathrm{A}}\right)$. We calculated adult female survival as $N_{\mathrm{A}}(t) /\left(N_{\mathrm{A}}(t-1)+N_{\mathrm{YL}}(t-1)\right)$. Due to extremely small population sizes in Mono Basin, calculations of adult female survival exceeded 1.0 in three years when one (in 1996 and 2002) or two (in 2001) additional females were observed in year $t$ than those known to be alive in the previous year $t-1$; survival in these cases was truncated at 1.0. While field surveys were highly successful at being near-complete census counts, these calculations demonstrate error in the data that we account for later. Yearling survival was calculated as $N_{\mathrm{YL}}(t) / N_{\mathrm{L}}(t-1)$, assuming equal survival among males and females since 
newborn lambs were not identified by sex. Fecundity was estimated as the number of female lambs per adult females or $N_{\mathrm{L}}(t) / N_{\mathrm{A}}(t)$, assuming that only adult females successfully reproduced. Again, given the influence of demographic stochasticity inherent with small sample sizes we used available data on the sex of yearlings in year $t+1$ to correct for known numbers of female lambs in year $t$, and assumed a 50:50 sex ratio for lambs of unknown gender.

Raw vital rate estimates included both process variance, the true biological variation in a rate due to spatial and temporal factors (including environmental and demographic stochasticity), and sampling variance, arising from inherent uncertainty in parameter estimation (Link and Nichols 1994). Because we were only interested in the influence of process variance in vital rate parameters on SNBS population performance (Mills and Lindberg 2002), we used the method of Kendall (1998) to remove sampling error from our binary vital rate data. We used the program Kendall.m in MATLAB (Morris and Doak 2002) to search over 1000 combinations of means and variances for each rate to estimate corrected population-specific vital rate parameters. For Mono Basin, in addition to estimating vital rates for the entire study period (hereafter referred

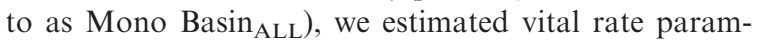
eters for the period the population was increasing

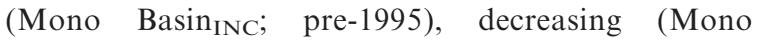
Basin $_{\mathrm{DEC}}$; post-1995), and for recent population trends

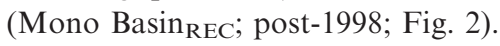

\section{Asymptotic analyses}

Because of differences in the timing of population surveys, we modeled Wheeler using a pre-birth pulse stage-based matrix model and Mono Basin and Langley using a post-birth pulse matrix model (Fig. 3). Both matrices were female-based, with a one-year projection interval derived from vital rates on the three observable stage classes. A primary difference between the matrices is the recruitment term $\left(R_{\mathrm{A}}\right)$ in the pre-birth model (the number of lambs that were born and survive their first year per adult female) and the fecundity term $\left(F_{\mathrm{A}}\right)$ in the post-birth pulse model (the number of lambs born per adult female). The other main difference is that the survival of two-year-olds $\left(S_{\mathrm{T}}\right)$ is included in the pre-birth model (survival from yearling to two-years-old), while the survival of yearlings $\left(S_{Y}\right)$ is included in the postbirth pulse model (survival from newborn lamb to yearling). Given that SNBS are long-lived $(\leq 20 \mathrm{yr})$, we consider adult female survival in both matrices $(\geq 2.1 \mathrm{yr}$ in the pre-birth model and $\geq 2.7 \mathrm{yr}$ in the post-birth model) to be equivalent.

We evaluated demographic trends for Wheeler, Langley, and Mono Basin across all years data were collected, and for Mono Basin ${ }_{\text {INC, }}$, Mono Basin ${ }_{\mathrm{DEC}}$, and

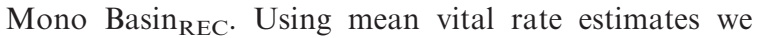
calculated the deterministic asymptotic population growth rate $(\lambda)$ for each population and time period.
Pre-birth pulse matrix model (Wheeler)

$$
\left[\begin{array}{ccc}
0 & 0 & R_{\mathrm{A}} \\
S_{\mathrm{T}} & 0 & 0 \\
0 & S_{\mathrm{A}} & S_{\mathrm{A}}
\end{array}\right]
$$

Post-birth pulse matrix model (Langley and Mono Basin)

$$
\left[\begin{array}{ccc}
0 & 0 & F_{A} \times S_{A} \\
S_{Y} & 0 & 0 \\
0 & S_{A} & S_{A}
\end{array}\right]
$$

FIG. 3. Pre- and post-birth pulse matrix models used to simulate female Sierra Nevada bighorn sheep population dynamics. Vital rates in the pre-birth pulse model are recruitment $\left(R_{\mathrm{A}}\right)$, two-yr-old female survival $\left(S_{\mathrm{T}}\right)$, and adult female survival $\left(S_{\mathrm{A}}\right)$. Vital rates in the post-birth pulse model are fecundity $\left(F_{\mathrm{A}}\right)$, yearling female survival $\left(S_{\mathrm{Y}}\right)$, and adult female survival $\left(S_{\mathrm{A}}\right)$.

We also calculated analytical sensitivity and elasticity values for vital rates of each population scenario. We evaluated differences between asymptotic stable stage distribution (SSD) and current SNBS stage distributions (from 2007 surveys) using a $\chi^{2}$ test and Keyfitz's $\Delta$, a measure of the Euclidean distance between actual and expected population vectors (Caswell 2001).

To determine life-history parameters having the greatest impact on SNBS performance, we next performed a conventional life-stage simulation analysis (LSA; Wisdom et al. 2000) to identify vital rate "importance" in terms of the amount of variation in $\lambda$ explained by variation in each vital rate. Specifically we generated 1000 matrices from distributions specifying the means, variances, and covariances of demographic rates. We then regressed asymptotic $\lambda$ from each matrix against each vital rate to measure the relative value of different rates in determining $\lambda$. Vital rate values for each time step were drawn from beta probability distributions (bounded between 0 and 1) using mean and variance estimates. We conducted analyses separately for uncorrelated and correlated vital rates. Correlated vital rates were based on the estimated covariance structure from population data (Appendix B).

\section{Non-asymptotic LSA}

We extended LSA to non-asymptotic projections using field surveys from 2007 to specify the initial number of individuals in each stage class. Initial population vectors describing the number of lambs, yearlings, and adults for each population were 6,4 , and 34 for Wheeler; 9, 11, and 38 for Langley; and 4, 3, and 11 for Mono Basin. Each matrix was projected for periods of 5 and 10 years, time periods of management interest for the SNBS Recovery Program and the U.S. Fish and Wildlife Service.

In each simulation, the population vector for each year was multiplied by a randomly drawn matrix, where 
vital rate values were generated from beta distributions given the means and variances specific to each population. Because SNBS populations were small, we also included demographic stochasticity into simulations, as incorporated by Mills and Smouse (1994) for survival and reproduction. Over the course of each simulation we tracked the total change in population size $(\Delta N)$ over the projection interval and stochastic lambda $\left(\lambda_{\mathrm{s}}\right)$ calculated as $\left(N_{T \max } / N_{0}\right)^{1 / T \max }$. For each model we ran 1000 replicates and calculated average $\Delta N$ and $\lambda_{\mathrm{s}}$ across replicated simulations. Using this approach, we then evaluated a series of scenarios for each SNBS population to predict performance given (1) baseline or nonmanipulated vital rate values, (2) proportional one-at-atime increases in each individual vital rate, and (3) potential management activities.

The baseline scenario for each population used nonmanipulated vital rate values for 5- and 10-year projections. For Mono Basin, we used vital rate values post-1998 (Mono Basin ${ }_{\text {REC }}$ ) as they are representative of recent trends (Fig. 2).

Next, we simulated a one-at-a-time $5 \%$ proportional increase in each mean vital rate value while maintaining estimated variances around those rates. We did this to compare vital rate assessments from asymptotic analyses to those simulated from non-asymptotic models and determine whether management recommendations would be identical. As with baseline projections these scenarios were simulated for 5 and 10 years. All vital rates were individually increased for each population except for adult female survival at Langley, where high baseline survival $(97.7 \%$ ) prevented a biologically meaningful increase.

Finally, we simulated the potential impact of two management activities that have been proposed for SNBS conservation: predator control and augmentations. Management scenarios were simulated for five years, a time period congruent with recovery effort assessment. While we include these simulations as an example of how demographic models can be used to evaluate potential management scenarios, it is important to acknowledge that other actions may be equally or more effective at boosting SNBS performance (U.S. Fish and Wildlife Service 2007).

Mountain lions are the primary predators of SNBS and have been implicated in impeding their recovery (Wehausen 1996, U.S. Fish and Wildlife Service 2007). Additionally, other studies quantifying the effect of mountain lions on bighorn sheep have found that predation can cause substantial reductions in survival and recruitment rates (Ross et al. 1997, Hayes et al. 2000, Kamler et al. 2002, Rominger et al. 2004, FestaBianchet et al. 2006, Rominger and Goldstein 2008). While most studies monitor predation rates on only adult bighorn sheep, younger stage classes may be subject to even higher rates of lion predation (Ross et al. 1997, Festa-Bianchet et al. 2006). While lion removal is expected to benefit SNBS, the precise effects on vital rates are unknown. Based on predation rates from other studies and cause-specific mortality data from SNBS, we conservatively modeled the effects of predator control on vital rates in two ways: (1) a proportional 5\% increase across all rates, and (2) a 5\% proportional increase in $S_{\mathrm{A}}$ but a $10 \%$ increase in vital rates of younger stage classes.

In addition to predator control, we modeled the impact of an augmentation on the performance of each SNBS population. CDFG has considered augmenting populations with 5-10 adult females to stimulate population growth, realistic numbers given limited source stock for translocations. We modeled such increases by altering the initial population vector to reflect potential augmentations, while leaving vital rate values unchanged.

\section{RESUlts}

\section{Estimated vital rate parameters}

Vital rate values showed strong spatial and temporal variation (Table 1; Fig. 4), with Langley having the highest mean vital rates, followed by Wheeler, and then Mono Basin. After sampling variance was separated from process variance, yearling and two-year-old survival were generally the most variable vital rates across all populations and years. However, when analyses for Mono Basin were conducted for different trend periods, adult survival was the most variable vital rate for Mono Basin ${ }_{\text {DEC }}$ and Mono Basin REC $_{\text {(Table 1). }}$ Contrary to typical patterns of ungulate dynamics, adult survival had greater process variation than recruitment at Wheeler, and than fecundity at Mono Basin ${ }_{\mathrm{ALL}}$, Mono Basin ${ }_{\text {DEC }}$, and Mono Basin ${ }_{\text {REC }}$.

\section{Asymptotic analyses}

Based on average vital rates, asymptotic $\lambda$ was 1.09 for Wheeler, 1.18 for Langley, 0.99 for Mono Basin $\mathrm{ALL}$, 1.07 for Mono Basin ${ }_{\text {INC }}, 0.96$ for Mono Basin ${ }_{\text {DEC }}$, and 1.02 for Mono Basin ${ }_{\text {REC }}$. None of the observed stage distributions from 2007 field surveys were significantly different from SSD (all populations $\chi^{2}<0.05, \mathrm{df}=2, P$ $>0.97$; also Keyfitz's $\Delta \leq 0.10$ for all herds). Consistent with studies of other ungulates and long-lived species, adult female survival had the highest analytical sensitivity and elasticity values across all populations and time periods (Table 1).

LSA results showed that the proportion of variation in $\lambda$ attributable to each vital rate differed across SNBS populations (Table 1). Langley and Mono Basin ${ }_{\text {INC }}$ exhibited classic patterns of ungulate dynamics where younger stage classes were responsible for most of the variation in $\lambda$ (Fig. 5; Gaillard et al. 1998, 2000, Raithel et al. 2007). In Langley, recruitment explained the highest percentage of variation in $\lambda(74 \%)$, while for Mono Basin INCREASING $_{\text {yearling survival explained }}$ most of the variation (63\%). Conversely, adult survival was most strongly associated with $\lambda$ for Wheeler, Mono Basin $_{\mathrm{ALL}}$, Mono Basin ${ }_{\text {DEC }}$, and Mono Basin ${ }_{\text {REC }}$ ex- 
TABLE 1. Sierra Nevada bighorn sheep (Ovis canadensis sierrae) parameter estimates used in vital rate analyses, including the number of years data were collected $(n)$, and vital rate means estimated directly from survey data (estimated) and corrected with a maximum-likelihood approach to account for sampling variance (corrected).

\begin{tabular}{|c|c|c|c|c|c|c|c|c|c|c|c|}
\hline Population & $n$ & $\begin{array}{c}\text { Estimated } \\
\text { mean }\end{array}$ & $\begin{array}{l}\text { Corrected } \\
\text { mean }\end{array}$ & Min. & Max. & $\begin{array}{c}\text { Total } \\
\text { variance }\end{array}$ & $\begin{array}{c}\text { Process } \\
\text { variance }\end{array}$ & Sens. & Elast. & $\begin{array}{c}r^{2} \text { of } \\
\lambda \text { Uncorr. }\end{array}$ & $\begin{array}{c}r^{2} \text { of } \\
\lambda \text { Corr. }\end{array}$ \\
\hline \multicolumn{12}{|l|}{ Wheeler } \\
\hline \multicolumn{12}{|l|}{ All years } \\
\hline Recruitment & 13 & 0.3225 & 0.3126 & 0.2268 & 0.4254 & 0.0216 & 0.0055 & 0.4242 & 0.1211 & 0.1447 & 0.2893 \\
\hline Two-year survival & 13 & 0.7561 & 0.7295 & 0.4444 & 1.0000 & 0.0355 & 0.0138 & 0.1818 & 0.1211 & 0.0678 & 0.5872 \\
\hline Adult survival & 13 & 0.9168 & 0.9197 & 0.6923 & 1.0000 & 0.0097 & 0.0083 & 0.9019 & 0.7577 & 0.8243 & 0.8740 \\
\hline \multicolumn{12}{|l|}{ Langley } \\
\hline \multicolumn{12}{|l|}{ All years } \\
\hline Fecundity & 11 & 0.3409 & 0.3311 & 0.1670 & 0.5450 & 0.0354 & 0.0068 & 0.4495 & 0.1265 & 0.7408 & 0.7506 \\
\hline Yearling survival & 9 & 0.8986 & 0.8722 & 0.5556 & 1.0000 & 0.0243 & 0.0115 & 0.1706 & 0.1265 & 0.1759 & 0.0870 \\
\hline Adult survival & 9 & 0.9735 & 0.9772 & 0.9000 & 1.0000 & 0.0022 & 0.0001 & 1.0516 & 0.8735 & 0.0579 & 0.0002 \\
\hline \multicolumn{12}{|l|}{ Mono Basin } \\
\hline \multicolumn{12}{|l|}{ All years } \\
\hline Fecundity & 22 & 0.3048 & 0.2934 & 0.0556 & 0.5625 & 0.0126 & 0.0003 & 0.3558 & 0.1054 & 0.0051 & 0.1190 \\
\hline Yearling survival & 21 & 0.6115 & 0.6006 & 0.1000 & 1.0000 & 0.0461 & 0.0339 & 0.1738 & 0.1054 & 0.0350 & 0.3607 \\
\hline Adult survival & 17 & 0.8625 & 0.8583 & 0.4286 & 1.0000 & 0.0276 & 0.0189 & 1.0325 & 0.8946 & 0.9459 & 0.9651 \\
\hline \multicolumn{12}{|l|}{ Increasing (pre-1995) } \\
\hline Fecundity & 8 & 0.2930 & 0.2716 & 0.1857 & 0.4444 & 0.0054 & 0.0003 & 0.4275 & 0.1086 & 0.0383 & 0.5134 \\
\hline Yearling survival & 7 & 0.7223 & 0.7364 & 0.8182 & 1.0000 & 0.0343 & 0.0217 & 0.1577 & 0.1086 & 0.6298 & 0.7489 \\
\hline Adult survival & 5 & 0.9019 & 0.9207 & 0.8182 & 1.0000 & 0.0066 & 0.0003 & 1.0350 & 0.8914 & 0.3373 & 0.4791 \\
\hline \multicolumn{12}{|c|}{ Decreasing (post-1995) } \\
\hline Fecundity & 14 & 0.3116 & 0.3172 & 0.1333 & 0.5625 & 0.0172 & 0.0003 & 0.3072 & 0.1013 & 0.0059 & 0.0945 \\
\hline Yearling survival & 14 & 0.5562 & 0.5055 & 0.1000 & 1.0000 & 0.0452 & 0.0192 & 0.1927 & 0.1013 & 0.0170 & 0.3617 \\
\hline Adult survival & 12 & 0.8460 & 0.8395 & 0.4286 & 1.0000 & 0.0367 & 0.0288 & 1.0295 & 0.8987 & 0.9764 & 0.9835 \\
\hline \multicolumn{12}{|l|}{ Recent (post-1998) } \\
\hline Fecundity & 9 & 0.3315 & 0.3360 & 0.2000 & 0.4000 & 0.0073 & 0.0003 & 0.3632 & 0.1200 & 0.0000 & 0.0712 \\
\hline Yearling survival & 8 & 0.6769 & 0.6740 & 0.5000 & 0.8000 & 0.0075 & 0.0003 & 0.1811 & 0.1200 & 0.0012 & 0.0158 \\
\hline Adult survival & 8 & 0.8647 & 0.8563 & 0.5556 & 1.0000 & 0.0242 & 0.0110 & 1.0450 & 0.8800 & 0.9964 & 0.9963 \\
\hline
\end{tabular}

Note: Also provided for each vital rate are ranges (Min., minimum; Max., maximum), variances, sensitivities (Sens.), elasticities (Elast.), and the proportion of variation in the population growth rate explained ( $r^{2}$ of $\left.\lambda\right)$, given uncorrelated (Uncorr.) and correlated (Corr.) vital rates.

plaining $>82 \%$ of the variation in these growth rates (Table 1; Fig. 5). When we incorporated correlations among vital rates into LSA (Appendix B), rankings of the relative importance of different rates were qualitatively the same but there were differences in the amount of variance in $\lambda$ explained (Table 1).

\section{Non-asymptotic analyses}

Because our populations were close to SSD (see Results: Asymptotic analyses), our non-asymptotic LSA simulations incorporating field-estimated population sizes and initial stage structures, as well as demographic stochasticity and short time periods, largely agreed with those from asymptotic LSA results. Predictions from both showed that increases in adult female survival would have the greatest recovery benefit for Wheeler and Mono Basin, while increases in vital rates of the younger stage classes would be most beneficial for Langley (Table 2). When vital rates were simulated to individually increase by the same proportional amount, adult survival had the greatest effect on projected median population sizes in Wheeler and Mono Basin. At Langley, however, while asymptotic simulations clearly predicted that fecundity would be most beneficial for population performance, non-asymptotic simulations demonstrated that an increase in either fecundity or yearling survival would result in essentially equivalent gains in population size (Table 2). Thus, given simulation results, recovery efforts would almost equally benefit from increases in either stage class, a potentially critical observation, as certain rates may be easier to manage than others. Correlations among vital rates had no qualitative effect on results when included in population simulations (Appendix C).

Simulations of potential management actions on SNBS populations suggest that effective conservation activities are largely population-specific (Table 3). Given the two scenarios we modeled, for Wheeler it appears that predator control would be more successful than augmentations at increasing population size in the short term. For Mono Basin, effects of predator control and augmentations were similar, although the one-time addition of 10 adult females was predicted to have the greatest effect on the population (Table 3), a result largely driven by its small size. For Langley, impacts of either management action appear to be similar. Because baseline vital rate values are already high, there is not predicted to be much gain in size over the next five years 

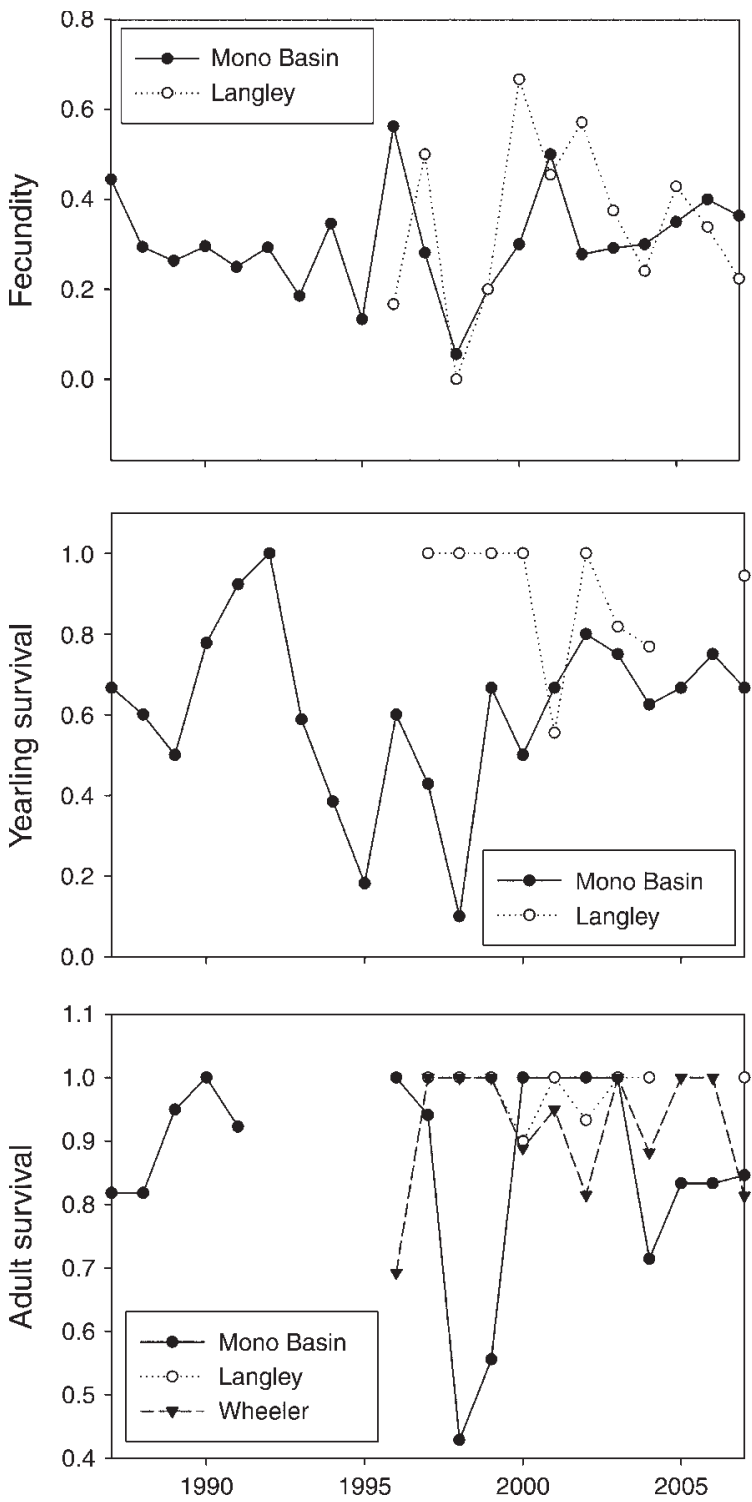

FIG. 4. Annual mean vital rates for the Mono Basin, Langley, and Wheeler populations of Sierra Nevada bighorn sheep, 1985-2007. Due to the timing of field surveys at Wheeler, adult female survival is the only vital rate directly comparable to the other populations.

from either scenario, with only a $7-20 \%$ proportional increase in numbers over baseline projections.

\section{Discussion}

Vital rate analyses elucidated findings relevant both for the conservation of SNBS and for the general application of these approaches to the management of declining and endangered populations. First, we found that SNBS vital rate values showed high spatial and temporal variation, resulting in population-specific dynamics that did not always fit general expectations from other ungulates, particularly during the period of population decline. We also found that while asymptotic approaches were generally applicable to SNBS conservation planning, our non-asymptotic models yielded nonintuitive results that could be important for managers. Finally, we found that due to extreme differences in the dynamics of individual populations, effective management strategies for endangered species recovery may often need to be population-specific.

Vital rate parameters showed dramatic spatial and temporal variation (Table 1; Fig. 4), as SNBS populations have experienced increasing and decreasing trajectories both within herds (Mono Basin) and recently
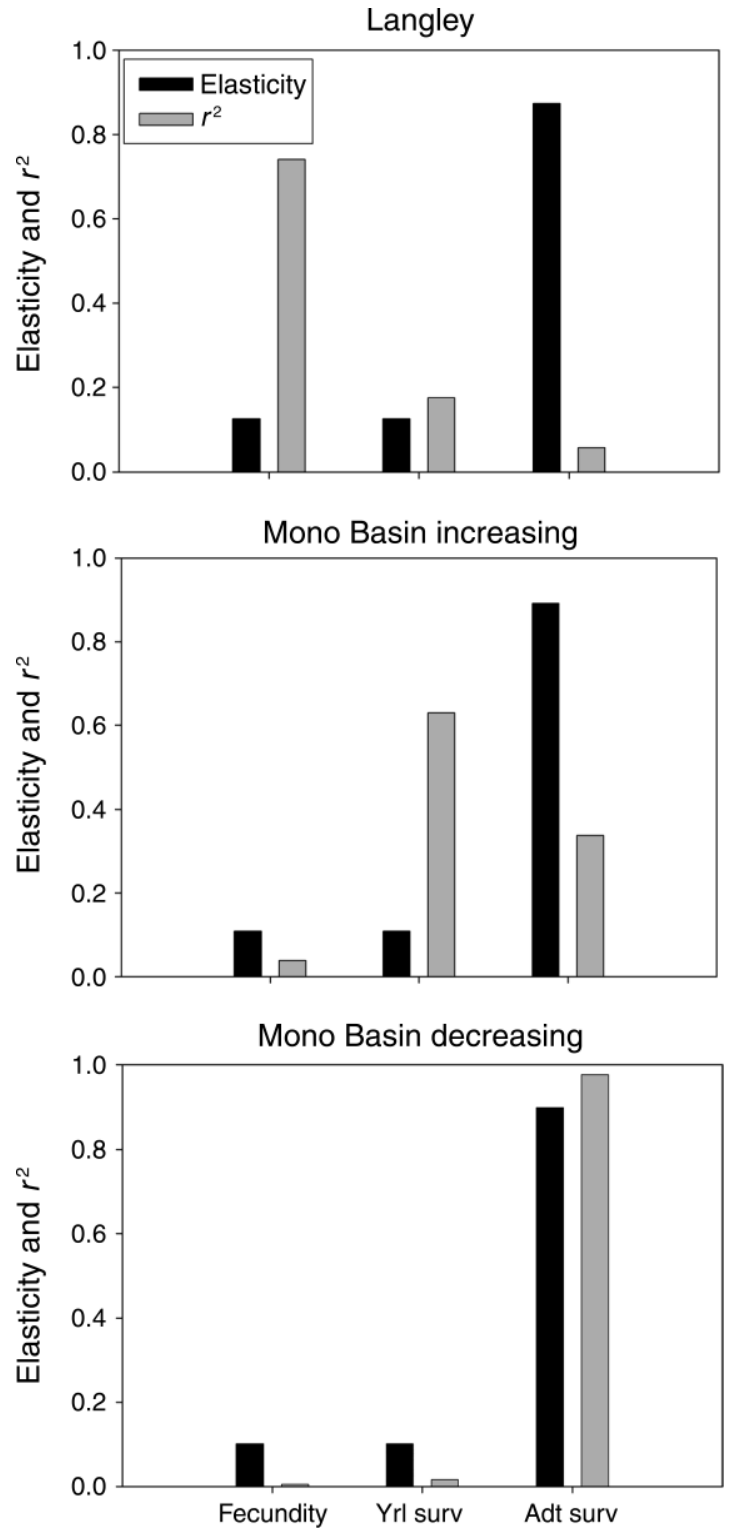

FIG. 5. Analytical elasticities and coefficients of determination $\left(r^{2}\right)$ for Sierra Nevada bighorn sheep fecundity, yearling survival ("Yrl surv"), and adult survival ("Adt surv") rates in the Mono Basin and Langley populations. Values are shown for years when the Mono Basin population was increasing vs. decreasing. 
TABLE 2. Median predicted sizes $\left(N_{T \max }\right)$ and stochastic growth rates $\left(\lambda_{\mathrm{s}}\right)$ of Sierra Nevada bighorn sheep populations projected over 5 and 10 years.

\begin{tabular}{|c|c|c|c|c|c|}
\hline Population scenario & $\begin{array}{c}\text { Projected } \\
\text { years }\end{array}$ & $\begin{array}{c}\text { Median } \\
N_{T \max }\end{array}$ & $\begin{array}{c}\% \uparrow \text { from } \\
\text { baseline }\end{array}$ & $\lambda_{\mathrm{s}}$ & $\operatorname{Var} \lambda_{\mathrm{s}}$ \\
\hline \multicolumn{6}{|l|}{ Wheeler } \\
\hline \multirow[t]{2}{*}{ Baseline } & 5 & 72 & & 1.0963 & 0.0024 \\
\hline & 10 & 110 & & 1.0938 & 0.0011 \\
\hline \multirow{2}{*}{ Increase $R_{\mathrm{A}}$ by $5 \%$} & 5 & 75 & 4.17 & 1.1081 & 0.0022 \\
\hline & 10 & 120 & 9.09 & 1.1026 & 0.0010 \\
\hline \multirow{2}{*}{ Increase $S_{\mathrm{Y}}$ by $5 \%$} & 5 & 73 & 1.39 & 1.1049 & 0.0022 \\
\hline & 10 & 117 & 6.36 & 1.1004 & 0.0011 \\
\hline \multirow[t]{2}{*}{ Increase $S_{\mathrm{A}}$ by $5 \%$} & 5 & 88 & 22.22 & 1.1384 & 0.0026 \\
\hline & 10 & 167 & 51.82 & 1.1340 & 0.0013 \\
\hline \multicolumn{6}{|l|}{ Langley } \\
\hline \multirow[t]{2}{*}{ Baseline } & 5 & 130 & & 1.1765 & 0.0005 \\
\hline & 10 & 295 & & 1.1760 & 0.0002 \\
\hline \multirow{2}{*}{ Increase $F_{\mathrm{A}}$ by $5 \%$} & 5 & 135 & 3.85 & 1.1841 & 0.0005 \\
\hline & 10 & 312 & 5.76 & 1.1832 & 0.0003 \\
\hline \multirow[t]{2}{*}{ Increase $S_{\mathrm{Y}}$ by $5 \%$} & 5 & 136 & 4.62 & 1.1845 & 0.0005 \\
\hline & 10 & 313 & 6.10 & 1.1834 & 0.0002 \\
\hline \multirow[t]{2}{*}{ Increase $S_{\mathrm{A}}$ by $5 \%$} & 5 & $\mathrm{~N} / \mathrm{A} \dagger$ & $\mathrm{N} / \mathrm{A}^{\dagger}$ & $\mathrm{N} / \mathrm{A}^{\dagger}$ & $\mathrm{N} / \mathrm{A}+$ \\
\hline & 10 & $\mathrm{~N} / \mathrm{A} \dagger$ & $\mathrm{N} / \mathrm{A} \dagger$ & $\mathrm{N} / \mathrm{A} \dagger$ & $\mathrm{N} / \mathrm{A} \dagger$ \\
\hline \multicolumn{6}{|l|}{ Mono Basin, post-1998 } \\
\hline \multirow[t]{2}{*}{ Baseline } & 5 & 19 & & 1.0006 & 0.0056 \\
\hline & 10 & 20 & & 1.0046 & 0.0035 \\
\hline \multirow[t]{2}{*}{ Increase $R_{\mathrm{A}}$ by $5 \%$} & 5 & 20 & 5.26 & 1.0113 & 0.0053 \\
\hline & 10 & 21 & 5.00 & 1.0085 & 0.0031 \\
\hline \multirow[t]{2}{*}{ Increase $S_{\mathrm{Y}}$ by $5 \%$} & 5 & 20 & 5.26 & 1.0100 & 0.0054 \\
\hline & 10 & 21 & 5.00 & 1.0099 & 0.0030 \\
\hline \multirow[t]{2}{*}{ Increase $S_{\mathrm{A}}$ by $5 \%$} & 5 & 24 & 26.32 & 1.0486 & 0.0053 \\
\hline & 10 & 31 & 55.00 & 1.0461 & 0.0027 \\
\hline
\end{tabular}

Note: Initial population sizes and stage distributions were parameterized from 2007 field surveys.

$\uparrow$ An increase in adult female survival for Langley was not modeled since the baseline mean value was already so high $(97.7 \%)$.

among herds (i.e., Langley vs. Mono Basin). Also, populations with seemingly synchronous trajectories, such as Langley and Wheeler, were shown to be driven by entirely different vital rates (fecundity at Langley and adult survival at Wheeler). These differences suggest substantial variation in the spatial and temporal factors determining SNBS demographic processes, but there is uncertainty about the specific factors driving this variation. Differences in low-elevation winter range habitat use are suspected to influence SNBS demo-

TABLE 3. Predicted median size $\left(N_{T \max }\right)$ and growth rate $\left(\lambda_{\mathrm{s}}\right)$ of female Sierra Nevada bighorn sheep populations given hypothetical management scenarios for a five-year period.

\begin{tabular}{|c|c|c|c|c|c|}
\hline Population & Potential effect of management & Median $N_{T \max }$ & $\lambda_{\mathrm{s}}$ & $\operatorname{Var} \lambda_{\mathrm{s}}$ & $\% \uparrow$ from baseline \\
\hline \multicolumn{6}{|l|}{ Predator control } \\
\hline \multirow[t]{2}{*}{ Wheeler } & increase $R_{\mathrm{A}}, S_{\mathrm{Y}}$, and $S_{\mathrm{A}}$ by $5 \%$ & 94 & 1.1540 & 0.0022 & 30.56 \\
\hline & increase $R_{\mathrm{A}}$ and $S_{\mathrm{Y}}$ by $10 \%, S_{\mathrm{A}}$ by $5 \%$ & 100 & 1.1669 & 0.0025 & 38.89 \\
\hline \multirow[t]{2}{*}{ Langley } & increase $F_{\mathrm{A}}$ and $S_{\mathrm{Y}}$ by $5 \%$ & 140 & 1.1921 & 0.0005 & 7.69 \\
\hline & increase $F_{\mathrm{A}}$ and $S_{\mathrm{Y}}$ by $10 \%$ & 149 & 1.2077 & 0.0006 & 14.62 \\
\hline \multirow[t]{2}{*}{ Mono Basin } & increase $F_{\mathrm{A}}, S_{\mathrm{Y}}$, and $S_{\mathrm{A}}$ by $5 \%$ & 25 & 1.0603 & 0.0053 & 31.58 \\
\hline & increase $F_{\mathrm{A}}$ and $S_{\mathrm{Y}}$ by $10 \%, S_{\mathrm{A}}$ by $5 \%$ & 27 & 1.0700 & 0.0055 & 42.11 \\
\hline \multicolumn{6}{|l|}{ Augmentation } \\
\hline \multirow[t]{2}{*}{ Wheeler } & augment 5 adult females & 80 & 1.0985 & 0.0022 & 11.11 \\
\hline & augment 10 adult females & 90 & 1.1000 & 0.0024 & 25.00 \\
\hline \multirow[t]{2}{*}{ Langley } & augment 5 adult females & 143 & 1.1784 & 0.0006 & 10.00 \\
\hline & augment 10 adult females & 156 & 1.1800 & 0.0005 & 20.00 \\
\hline \multirow{2}{*}{ Mono Basin } & augment 5 adult females & 25 & 1.0067 & 0.0033 & 31.58 \\
\hline & augment 10 adult females & 31 & 1.0335 & 0.0031 & 63.16 \\
\hline
\end{tabular}

Notes: Each scenario prediction is compared to baseline predictions. Predator control was modeled by first simulating a $5 \%$ increase in all vital rates for each population. For Wheeler increases in recruitment $\left(R_{\mathrm{A}}\right)$, two-year-old female survival $\left(S_{\mathrm{T}}\right)$, and adult survival $\left(S_{\mathrm{A}}\right)$ were simulated, while for Langley and Mono Basin increases in fecundity $\left(F_{\mathrm{A}}\right)$, yearling survival $\left(S_{\mathrm{Y}}\right)$, and adult survival $\left(S_{\mathrm{A}}\right)$ were simulated. In a second predator control scenario, we modeled an increase in $R_{\mathrm{A}}$ and $S_{\mathrm{T}}$ or $F_{\mathrm{A}}$ and $S_{\mathrm{Y}}$ by $10 \%$ and an increase in $S_{\mathrm{A}}$ by $5 \%$. We also simulated population effects of a one-time augmentation of 5 or 10 adult females into each population. 
graphic rates (U.S. Fish and Wildlife Service 2007), particularly for the Mono Basin. While predation rates are not known over the entire period of this study, cause-specific mortality data collected over the past five years suggest that predation pressure varies among herds (CDFG, unpublished data); Langley and Mono Basin generally experience low mountain lion predation, while Wheeler experiences moderate predation. Impacts of disease and genetic diversity may also differentially influence SNBS demographic rates, but the effects of these factors are currently unknown.

The dominant paradigm for ungulates is that adult female survival has the highest elasticity, but its low variation causes it to contribute relatively little to changes in the population growth rate compared to juvenile survival, which has low elasticity but high variation, making it the primary determinant of population change (Gaillard et al. 1998, 2000, Gaillard and Yoccoz 2003, Raithel et al. 2007). In contrast to this paradigm, we found that while elasticity results were consistent across all SNBS herds and followed classic expectations, vital rates explaining the most variation in population growth differed among herds and contradicted theoretical expectations. For example, in Wheeler, Mono Basin $\operatorname{ALL}_{\text {, Mono Basin }}$ DEC, and Mono Basin $_{\text {REC }}$ variation was higher in adult survival than recruitment or fecundity, contributing to the pattern that adult survival explained the highest proportion of variation in population growth. Only growth rates for Langley and Mono Basin INC followed general ungulate life-history expectations, driven by changes in fecundity and yearling survival, respectively. To date, few ungulate studies have observed such variation in the importance of different vital rates within or among populations (Albon et al. 2000, Coulson et al. 2005, Nilsen et al. 2009), and consequently, the implications of such variation for conservation and management purposes have been likely overlooked.

Such shifts in the means and variances of key vital rates may be largely responsible for declining and endangered populations. Owen-Smith and Mason (2005) found that decreases in adult survival were responsible for African ungulate populations that transitioned from stable trajectories to declining ones. That this pattern was contrary to other studies of ungulate dynamics was attributed to the fact that most investigations have been conducted in temperate zones, not tropical ones with a large suite of predators. However, our temperate-region Mono Basin population provides similar evidence for how changes in vital rate values may trigger a declining growth rate. Mono Basin $_{\text {INC }}$ was characterized by high adult survival $(92 \%)$ with extremely low process variability $(0.0003)$, and a growth rate that was most closely associated with survival of the widely varying yearling stage class. Mono Basin $_{\text {DEC }}$, on the other hand, was characterized by much lower mean adult survival ( $84 \%$ ), with almost a 100 -fold increase in process variation (0.0288), and a growth rate almost entirely determined by adult survival. Pfister (1998) suggested that demographic rates were unlikely to be both highly variable and have a large effect on the growth rate of a population. This observation, however, may only be relevant to stable or increasing populations. In small, declining, or endangered populations it might be quite common for vital rates with the greatest elasticity to also be highly variable and have a large impact on population change (Wisdom et al. 2000, Schmidt et al. 2005, Nilsen et al. 2009). In fact, several studies on long-lived species have associated population declines to decreases in adult survival, the rate expected to have the highest elasticity (Wehausen 1996, Flint et al. 2000, Rubin et al. 2002, Pistorius et al. 2004, Wittmer et al. 2005).

As anthropomorphic factors continue to reduce wildlife populations, understanding the processes that govern the fate of small populations is becoming increasingly urgent. Because data are often sparse for threatened and endangered species, it seems intuitive to apply results of vital rate analyses from healthy, wellstudied species or populations to those of conservation concern. Our results, however, illustrate the potential danger of this approach. Based on studies of other ungulate populations, a reasonable assumption would be to focus SNBS recovery efforts on increasing juvenile survival, as this rate has been responsible for the dynamics of other healthy herds of large herbivores. Data from SNBS suggest, however, that it is a decrease in adult survival that is the primary driver of SNBS declines and that it should be the focus of monitoring and management activities. Shifts in the means or variances of key vital rates, particularly as they differ from life-history expectations may frequently result in endangered, small, or declining populations. As a result, it may be necessary to conduct a detailed demographic analysis of these populations to identify appropriate management targets.

Recent papers have stressed the importance of considering transient dynamics with initial population vectors when making short-term predictions, as those based on asymptotic properties can yield misleading results (Fox and Gurevitch 2000, Koons et al. 2005, Fefferman and Reed 2006, Caswell 2007). This is particularly important for "slower" species, such as bighorn sheep, having longer life spans and lower reproductive potential (Koons et al. 2005). In spite of this, our non-asymptotic LSA approach, incorporating demographic stochasticity, initial population sizes, and short management time frames, conferred qualitatively similar results to asymptotic predictions. Close agreement between the methods is likely because SNBS stage class distributions were very similar to SSD, and thus short-term predictions were in close alignment with asymptotic expectations. For populations that are far from SSD, however, our non-asymptotic approach should yield more accurate short-term predictions, particularly for populations of management and conser- 
vation concern. Such an approach would be particularly valuable for making predictions about populations that have been recently "bumped" from SSD, such as after a major perturbation or mortality event (i.e., a disease episode) that differentially affects distinct life stages, or for newly reintroduced populations having artificially skewed (and known) initial stage distributions.

While our non-asymptotic simulations agreed with asymptotic LSA results in terms of identifying vital rates contributing most to the variation in population growth, they also yielded some non-intuitive results relevant to management. In some cases, we found that targeting an entirely different rate than the one identified by asymptotic LSA, gave essentially equivalent results over time periods of management interest. Depending on the ability of management actions to manipulate individual vital rates, such simulations could recognize equally viable recovery alternatives that would not be apparent from asymptotic analyses alone. For example, asymptotic analyses found that the growth rate at Langley was most strongly correlated with fecundity rates; however, non-asymptotic models predicted that an increase in either fecundity or yearling survival would yield virtually identical results in population performance over the time period of management interest. While we recognize that the detailed demographic data needed to conduct nonasymptotic analyses do not exist for most endangered species, we feel that when data are available it is important to incorporate such approaches into population models to avoid simplifying assumptions. When such data are not available, however, traditional LSA will still provide critical information for management.

To design successful conservation plans, managers must first know how different actions will affect key vital rates and to what degree. The two management scenarios we simulated, predator control (an increase in mean vital rate values) and augmentations (an increase in number of adult females in the initial population vector), illustrated that effective strategies appear to be largely population-specific. For example, from the two scenarios we modeled it appears that predator control will be most effective for stimulating the Wheeler population, while an augmentation may be most effective for a short-term boost in performance at Mono Basin. Given the current growth rate of the Langley herd, management actions are not predicted to have an appreciable impact, and thus recovery efforts could be better invested elsewhere. While predator control and augmentations are two management options currently being considered for SNBS recovery, other options considered in the Recovery Plan include habitat enhancement, genetic management, and disease prevention (U.S. Fish and Wildlife Service 2007). Unfortunately we have too little information from field data or the literature to adequately model the effects of those activities on SNBS vital rates.

Our models incorporated numerous factors that we assumed were important for short-term SNBS dynamics such as environmental and demographic stochasticity, correlations (positive and negative) among vital rates, realistic management time frames, and actual initial population vectors. We did not, however, include functional changes in vital rate values with respect to population size, as would be expected with density dependence. Instead, we assumed that negative density dependence would not be an issue for this endangered subspecies at the small population sizes and short time periods we modeled (Beissinger and Westphal 1998). Additionally, while we simulated the numeric response of augmentations on SNBS population dynamics, we did not account for potential positive density dependence (Allee effects) on mean vital rate values. If either negative or positive density dependence occurs in SNBS populations, our predictions about population change could be either over- or underestimated, and any such process variation would be falsely attributed to stochasticity. We also did not include a senescent stage class in our demographic models, as these animals are not uniquely identifiable in the field. In an analysis based on marked individuals, Nilsen et al. (2009) found that the inclusion of a senescent stage class slightly decreased the contribution of adult survival to population growth, but there were no qualitative differences. Because our estimates of adult female survival and reproduction are based on near-complete census counts (which include both prime-age and senescent individuals), we assume that the demographic impacts of senescent animals are incorporated into our projection models. As with all matrix model simulations, predicted results should be regarded on a relative, rather than absolute, basis (Beissinger and Westphal 1998, Morris and Doak 2002, Reed et al. 2002).

In conclusion, we demonstrate that the relative contribution of different vital rates to population growth may vary among populations of the same species, and within the same geographic region, not following expectations from life-history theory. As a result, inferences about the importance of different rates from one species or population may not be applicable to another, and could potentially misdirect critical resources if inappropriately employed within conservation programs. Furthermore, endangered species recovery programs should be responsive to deviations between observed vital rate values and those predicted from classic life-history expectations. Such departures may be largely responsible for population declines and serve as important targets for monitoring programs and management actions.

\section{ACKNOWLEDGMENTS}

We thank all the people involved in collecting demographic data on SNBS including T. Blankinship, L. Bowermaster, L. Brown, M. Cahn, C. Chang, L. Chow, K. Ellis, D. German, A. Feinberg, J. Fusaro, L. Greene, D. Jensen, M. Kiner, K. Knox, P. Moore, R. Ramey II, C. Schroeder, T. Taylor, and S. Thompson. We are grateful to D. German, M. Hebblewhite, M. Kauffman, M. Mitchell, D. Pletscher, J.-M. Gaillard, and an 
anonymous reviewer for providing constructive comments on this manuscript. We also thank C. Hartway for her programming expertise in MATLAB. The California Department of Fish and Game and the Canon National Parks Science Scholars Program funded this work.

\section{Literature Cited}

Albon, S. D., T. N. Coulson, D. Brown, F. E. Guinness, J. M. Pemberton, and T. H. Clutton-Brock. 2000. Temporal changes in key factors and key age groups influencing the population dynamics of female red deer. Journal of Animal Ecology 69:1099-1110.

Beissinger, S., and M. I. Westphal. 1998. On the use of demographic models of population viability in endangered species management. Journal of Wildlife Management 62: 821-841.

Biek, R., W. C. Funk, B. A. Maxell, and L. S. Mills. 2002. What is missing in amphibian decline research: insights from ecological sensitivity analysis. Conservation Biology 16:728734.

Bierzychudek, P. 1999. Looking backwards: assessing the projections of a transition matrix model. Ecological Applications 9:1278-1287.

Bleich, V. C., J. D. Wehausen, K. R. Jones, and R. A. Weaver. 1990. Status of bighorn sheep in California, 1989 and translocations from 1971 through 1989. Desert Bighorn Council Transactions 34:24-26.

Caswell, H. 2001. Matrix population models: construction, analysis and interpretation. Second edition. Sinauer Associates, Sunderland, Massachusetts, USA.

Caswell, H. 2007. Sensitivity analysis of transient population dynamics. Ecology Letters 10:1-15.

Citta, J. J., and L. S. Mills. 1999. What do demographic sensitivity analyses tell us about controlling brown-headed cowbirds? Studies in Avian Biology 18:121-134.

Clutton-Brock, T. H., and T. Coulson. 2002. Comparative ungulate dynamics: the devil is in the detail. Philosophical Transactions of the Royal Society B 357:1285-1298.

Coulson, T., J.-M. Gaillard, and M. Festa-Bianchet. 2005. Decomposing the variation in population growth into contributions from multiple demographic rates. Journal of Animal Ecology 74:789-801.

Crouse, D. T., L. B. Crowder, and H. Caswell. 1987. A stagebased population model for loggerhead sea turtles and implications for conservation. Ecology 68:1412-1423.

de Kroon, H., J. van Groenendael, and J. Ehrlén. 2000. Elasticities: a review of methods and model limitations. Ecology 81:607-618.

Fefferman, N. H., and J. M. Reed. 2006. A vital rate sensitivity analysis for nonstable age distributions and short-term planning. Journal of Wildlife Management 70:649-656.

Festa-Bianchet, M., T. Coulson, J.-M. Gaillard, J. T. Hogg, and F. Pelletier. 2006. Stochastic predation events and population persistence in bighorn sheep. Proceedings of the Royal Society B 273:1537-1543.

Flint, P. L., M. R. Petersen, C. P. Dau, J. E. Hines, and J. D. Nichols. 2000. Annual survival and site fidelity of Steller's eiders molting along the Alaska Peninsula. Journal of Wildlife Management 64:261-268.

Fox, G. A., and J. Gurevitch. 2000. Population numbers count: tools for near-term demographic analysis. American Naturalist 156:242-256.

Gaillard, J.-M., M. Festa-Bianchet, and N. G. Yoccoz. 1998. Population dynamics of large herbivores: variable recruitment with constant adult survival. Trends in Ecology and Evolution 13:58-63.

Gaillard, J.-M., M. Festa-Bianchet, and N. G. Yoccoz. 2001. Not all sheep are equal. Science 292:1499-1500.

Gaillard, J.-M., M. Festa-Bianchet, N. G. Yoccoz, A. Loison, and C. Toïgo. 2000. Temporal variation in fitness compo- nents and population dynamics of large herbivores. Annual Review of Ecology and Systematics 31:367-393.

Gaillard, J.-M., and N. G. Yoccoz. 2003. Temporal variation in survival of mammals: a case of environmental canalization? Ecology 84:3294-3306.

Hayes, C. L., E. S. Rubin, M. C. Jorgensen, R. A. Botta, and W. M. Boyce. 2000. Mountain lion predation of bighorn sheep in the Peninsular ranges, California. Journal of Wildlife Management 64:954-959.

Heppell, S. S. 1998. Application of life-history theory and population model analysis to turtle conservation. Copeia 2: 367-375.

Heppell, S. S., L. B. Crowder, and D. T. Crouse. 1996. Models to evaluate headstarting as a management tool for long-lived turtles. Ecological Applications 6:556-565.

Heppell, S., C. Pfister, and H. de Kroon. 2000. Elasticity analysis in population biology: methods and applications. Ecology 81:605-606.

Hill, M. 1975. Geology of the Sierra Nevada. University of California Press, Berkeley, California, USA.

Hoekman, S. T., T. S. Gabor, M. J. Petrie, R. Maher, H. R. Murkin, and M. S. Lindberg. 2006. Population dynamics of mallards breeding in agricultural environments in eastern Canada. Journal of Wildlife Management 70:121-128.

Kamler, J. F., R. M. Lee, J. C. deVos, Jr., W. B. Ballard, and H. A. Whitlaw. 2002. Survival and cougar predation of translocated bighorn sheep in Arizona. Journal of Wildlife Management 66:1267-1272.

Kendall, B. E. 1998. Estimating the magnitude of environmental stochasticity in survivorship data. Ecological Applications $8: 184-193$

Koons, D. N., J. B. Grand, B. Zinner, and R. F. Rockwell. 2005. Transient population dynamics: relations to life history and initial population size. Ecological Modelling 185:283297.

Koons, D. N., R. F. Rockwell, and J. B. Grand. 2006. Population momentum: implications for wildlife management. Journal of Wildlife Management 70:19-26.

Link, W. A., and J. D. Nichols. 1994. On the importance of sampling variance to investigations of temporal variation in animal population size. Oikos 69:539-544.

Merrill, J. A., E. G. Cooch, and P. D. Curtis. 2003. Time to reduction: factors influencing management efficacy in sterilizing overabundant white-tailed deer. Journal of Wildlife Management 67:267-279.

Mills, L. S. 2007. Conservation of wildlife populations: demography, genetics and management. Blackwell Publishing, Malden, Massachusetts, USA.

Mills, L. S., D. F. Doak, and M. J. Wisdom. 1999. Reliability of conservation actions based on elasticity analysis of matrix models. Conservation Biology 13:815-829.

Mills, L. S., D. F. Doak, and M. J. Wisdom. 2001. Elasticity analysis for conservation decision making: reply to Ehrlén et al. Conservation Biology 15:281-283.

Mills, L. S., and M. S. Lindberg. 2002. Sensitivity analysis to evaluate the consequences of conservation actions. Pages 338-366 in S. R. Beissinger and D. R. McCullough, editors. Population viability analysis. University of Chicago Press, Chicago, Illinois, USA.

Mills, L. S., and P. E. Smouse. 1994. Demographic consequences of inbreeding in remnant populations. American Naturalist 144:412-431.

Morris, W. F., and D. F. Doak. 2002. Quantitative conservation biology: theory and practice of population viability. Sinauer Associates, Sunderland, Massachussetts, USA.

Morris, W. F., and D. F. Doak. 2005. How general are the determinants of the stochastic population growth rate across nearby sites? Ecological Monographs 75:119-137.

Nilsen, E. B., J.-M. Gaillard, R. Andersen, J. Odden, D. Delorme, G. Van Laere, and J. D. C. Linnell. 2009. A slow life in hell or a fast life in heaven: demographic analyses of 
contrasting roe deer populations. Journal of Animal Ecology 78:585-594.

Norris, K., and N. McCulloch. 2003. Demographic models and the management of endangered species: a case study of the critically endangered Seychelles magpie robin. Journal of Applied Ecology 40:890-899.

Owen-Smith, N., and D. R. Mason. 2005. Comparative changes in adult vs. juvenile survival affecting population trends of African ungulates. Journal of Animal Ecology 74:762-773.

Pfister, C. A. 1998. Patterns of variance in stage-structured populations: evolutionary predictions and ecological implications. Proceedings of the National Academy of Sciences USA 95:213-218.

Pistorius, P. A., M. N. Bester, M. N. Lewis, F. E. Taylor, C. Campagna, and S. P. Kirkman. 2004. Adult female survival, population trend, and the implications of early primiparity in a capital breeder, the southern elephant seal (Mirounga leonina). Journal of Zoology 263:107-119.

Raithel, J. D., M. J. Kauffman, and D. H. Pletscher. 2007. Impact of spatial and temporal variation in calf survival on the growth of elk populations. Journal of Wildlife Management 71:795-803.

Reed, J. M., L. S. Mills, J. B. Dunning, Jr., E. S. Menges, K. S. McKelvey, R. Frye, S. R. Beissinger, M. C. Anstett, and P. Miller. 2002. Emerging issues in population viability analysis. Conservation Biology 16:7-19.

Rominger, E. M., and E. J. Goldstein. 2008. Evaluation of an 8year mountain lion removal management action on endangered desert bighorn sheep recovery. Wildlife Management Division Report. New Mexico Department of Game and Fish, Santa Fe, New Mexico, USA.

Rominger, E. M., H. A. Whitlaw, D. L. Weybright, W. C. Dunn, and W. B. Ballard. 2004. The influence of mountain lion predation on bighorn sheep translocations. Journal of Wildlife Management 68:993-999.

Ross, P. I., M. G. Jalkotzy, and M. Festa-Bianchet. 1997. Cougar predation on bighorn sheep in southwestern Alberta during winter. Canadian Journal of Zoology 75:771-775.
Rubin, E. S., W. M. Boyce, and E. P. Caswell-Chen. 2002. Modeling demographic processes in an endangered population of bighorn sheep. Journal of Wildlife Management 66: 796-810.

Sæther, B. E., and O. Bakke. 2000. Avian life history variation and contribution of demographic traits to the population growth rate. Ecology 81:642-653.

Schmidt, B. R., R. Feldmann, and M. Schaub. 2005. Demographic processes underlying population growth and decline in Salamandra salamandra. Conservation Biology 19: 1149-1156.

Silvertown, J., M. Franco, and E. Menges. 1996. Interpretation of elasticity matrices as an aid to the management of plant populations for conservation. Conservation Biology 10:591597.

Tuljapurkar, S., C. C. Horvitz, and J. B. Pascarella. 2003. The many growth rates and elasticities of populations in random environments. American Naturalist 162:489-502.

U.S. Fish and Wildlife Service. 2007. Recovery plan for the Sierra Nevada bighorn sheep. U.S. Fish and Wildlife Service, Sacramento, California, USA.

Wehausen, J. D. 1996. Effects of mountain lion predation on bighorn sheep in the Sierra Nevada and Granite Mountains of California. Wildlife Society Bulletin 24:471-479.

Wisdom, M. J., and L. S. Mills. 1997. Sensitivity analysis to guide population recovery: prairie chickens as an example. Journal of Wildlife Management 61:302-312.

Wisdom, M. J., L. S. Mills, and D. F. Doak. 2000. Life stage simulation analysis: estimating vital-rate effects on population growth for conservation. Ecology 81:628-641.

Wittmer, H. U., B. N. McLellan, D. R. Seip, J. A. Young, T. A. Kinley, G. S. Watts, and D. Hamilton. 2005. Population dynamics of the endangered mountain ecotype of woodland caribou (Rangifer tarandus caribou) in British Columbia, Canada. Canadian Journal of Zoology 83:407-418.

Yearsley, J. M. 2004. Transient population dynamics and shortterm sensitivity analysis of matrix population models. Ecological Modelling 177:245-258.

\section{APPENDIX A}

History and data collection of Sierra Nevada bighorn sheep populations (Ecological Archives A020-064-A1).

\section{APPENDIX B}

Correlation matrices for Sierra Nevada bighorn sheep population vital rates (Ecological Archives A020-064-A2).

\section{APPENDIX C}

Median predicted sizes and stochastic growth rates of Sierra Nevada bighorn sheep populations over 5 and 10 years given correlated vital rates, demographic stochasticity, and initial sizes and stage distributions from 2007 field surveys (Ecological Archives A020-064-A3). 